\title{
Development of an automatic, storage precipitation gauge for improved winter precipitation measurements
}

\author{
THOMAS WIESINGER, \\ Heinrich Tippl Str. 7, A-3012 Wolfsgraben, Austria
}

\author{
Shinichi Takami, Hiroyuki OHNo and Kotaro YoKoyama \\ Hokuriku National Agricultural Experiment Station, Joetsu, Niigata 943-01, Japan
}

\begin{abstract}
A high-precision, self-operating storage precipitation gauge was designed and field-tested. It consists of a cylinder-shaped container that incorporates antifreeze solution to melt snow and a quartz-crystal pressure sensor to detect mass of the contained liquid. Field trials showed performance to be at least equivalent to the Japanese standard gauge. A novel feature of the developed instrument is that it also measures a parameter related to wind speed, which is the basis for a catch correction. The instrument is simple, robust and can be battery-operated, therefore making it useful for winter precipitation measurements at sites where electric power supply is unavailable.
\end{abstract}

\section{INTRODUGTION}

Precipitation data are of primary importance for all hydrological studies. But there are few reliable data of winter precipitation in mountainous regions, due to technical difficulties with instrumentation and measurements.

Existing precipitation gauges are not suitable for our target areas where winter access is difficult and electric power supply is not available. Non-recording gauges with limited capacity, such as the MSC Nipher shielded snow gauge (Canada), the SMHI precipitation gauge (Sweden) and the Tretyakov precipitation gauge (Russia), must be emptied frequently, usually once a day (Goodison and others, 1981). Weighing-type precipitation gauges operate continously and unattended for up to one year (Goodison and others, 1981) but weighing is affected by wind, resulting in measurement errors (Foehner, 1978). The GEONOR gauge that is based on the vibrating-wire principle is capable of providing more reliable data (Huovila and others, 1988), but this method needs line current to operate. Likewise, the over-flow tipping-bucket gauge (the Japan Meteorological Agency standard) requires electric power to melt solid precipitation.

At remote or unattended sites storage-type gauges that melt solid precipitation with antifreeze solution have been used. Most of this type of gauge can only provide precipitation totals for a month or longer (Goodison and others, 1981). Floater-operated storage gauges have been developed to provide continous records, but this method is subject to errors caused by volume changes due to temperature changes over the season.

Another important problem for solid precipitation measurements is catch deficiency. Wind shields and/or modification of gauge collector shape improve catch efficiency but not completely (Larson, 1986). Alternatively, we can estimate "true precipitation" by applying correction procedures to gauge measurement (Sevruk, 1986). This seems more attractive and promising, but simple, accurate operational procedures for correction have not yet been developed.

The objective of this study was to develop an accurate,

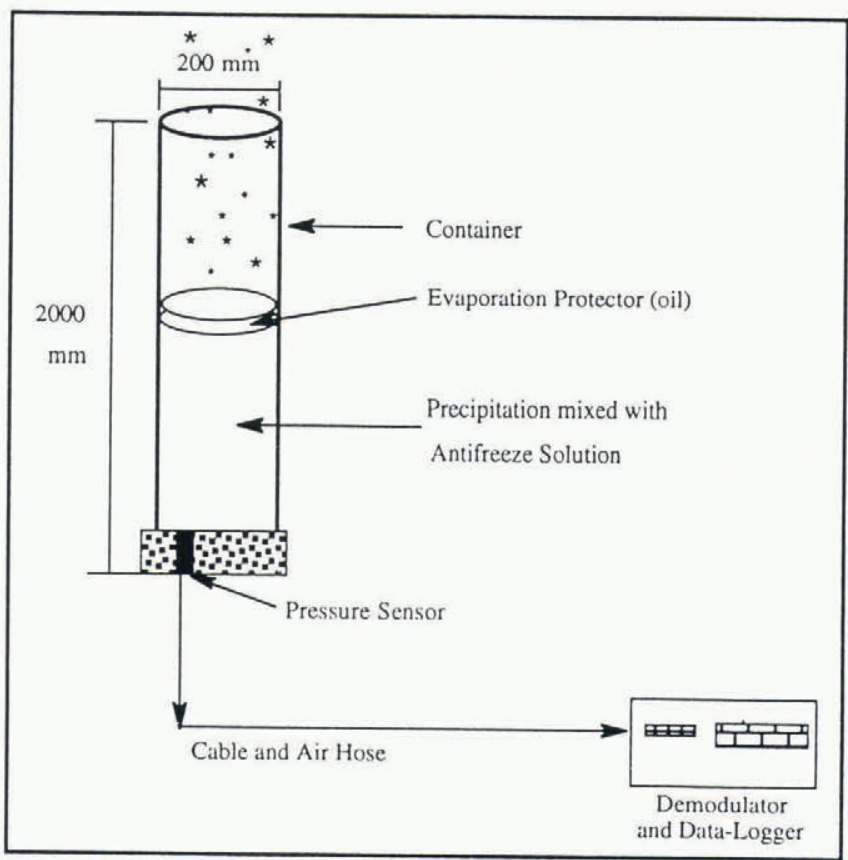

Fig. 1. Illustration of the precipitation gauge as developed and tested in 1991 and 1992 at the Hokuriku Agricultural Experiment Station, Joetsu, Japan. 
recording precipitation gauge for remote or unattended sites where heavy snowfall occurs in winter.

\section{DESIGN AND CONSTRUGTION}

The instrument consists of an open cylinder (the collectorcontainer) with a pressure sensor fitted to the cylinder bottom (Fig. 1). Antifreeze solution is charged in the cylinder and a thin layer of oil is used to retard evaporation of both antifreeze solution and water. The hydrostatic pressure of the liquid increases as precipitation accumulates in the container. This increase, when expressed in terms of water-column height in $\mathrm{mm}$, corresponds to the amount of precipitation caught during a given time period.

The collector-container used in this study was a $2000 \mathrm{~mm}$ high PVC cylinder with an orifice $200 \mathrm{~mm}$ in diameter. The cylinder was painted white. The orifice rim was a sharp ring made of brass. The gauge had no wind shield.

The pressure sensor uses a quartz crystal as transducer (Model QWP-841, Meisei Electric Co., Ltd.), which can be operated with either $12 \mathrm{VDC}$ batteries or $110 \mathrm{VAC}$. The sensor measures differential pressure between the reference and measuring cells. Since the reference cell was open to the atmosphere and the measuring cell to the liquid in the gauge container, the pressure of the liquid alone was supposed to be detected. The range of the sensor operation was $0-2000 \mathrm{~mm}$. Resolution of the pressure sensor was $0.1 \mathrm{~mm}$ and accuracy $\pm 0.05 \%$ of given quantity. The sensor accuracy was tested in the laboratory, eliminating the disturbing influences of temperature, evaporation and wind. Water was added 30 times to the container and the pressure increase was measured. The maximum error amounted to less than $0.1 \mathrm{~mm}$. Output signals were stored in a commonly available data-logger.

A mixture of $40 \%$ ethylene glycol and $60 \%$ ethanol was used as an antifreeze solution.

\section{PERFORMANCE}

\section{Scope and methods}

We conducted field tests to evaluate the performance of the instrument during two winters, 1990-91 and 1991-92 in Joetsu, Japan. The observation site was located on the Experimental Farm of the Hokuriku National Agricultural Experiment Station $\left(37^{\circ} 6^{\prime} 45^{\prime \prime} \mathrm{N}, 138^{\circ} 16^{\prime} 31^{\prime \prime} \mathrm{E}\right.$ and $11 \mathrm{~m}$ a.s.l.). The site was surrounded by open fields, mainly rice, and was more than $150 \mathrm{~m}$ away from trees and buildings.

The performance of the newly developed instrument (the "totalizer") was compared with the following gauges:

(1) Double Fence Intercomparison Reference (DFIR), with an unshielded and heated precision gauge surrounded by two large fences (1991-92 only);

(2) Japan Meteorological Agency (JMA) standard, shielded and heated (Yokogawa B-071);

(3) tipping bucket, unshielded and heated, (Yokogawa B-012);

(4) Belfort, unshielded and unheated (1990-91 only).

DFIR was set up according to the WMO specifications (WMO, 1985), except the gauge used was an unshielded and heated high-precision overflow gauge (Meisei QW-90). All gauges and the totalizer were installed on towers so that the orifice height was $3.5 \mathrm{~m}$ above the ground.

To establish a complete data set with all necessary information for the purposes of this study, we carried out continuous, automatic observations of air temperature, dew-point temperature, wind speed and direction, and solar radiation. Snow water equivalent was also measured continuously with a snow pillow. Additionally, we made daily snow water equivalent measurements of the snow cover and the new fallen snow by snow-core sampling to complement automatic measurements.

Table 1. Precipitation as measured at Joetsu, Japan, by different methods over the period 19-25 February 1991

\begin{tabular}{cccccc} 
Snow & Snow & \multicolumn{4}{c}{ Precipitation } \\
sampling & pillow & $\mathcal{F}$ Tipping & Totalizer \\
& & Belfort & bucket & $\#$
\end{tabular}

\begin{tabular}{lcccccc}
\hline & & & & & & \\
Precipitation $(\mathrm{mm})$ & 179 & 148 & 88 & 88 & 80 & 85 \\
Catch efficiency & 1 & 0.82 & 0.48 & 0.48 & 0.38 & 0.44 \\
& 1 & 1 & 0.59 & 0.59 & 0.54 & 0.57 \\
Gauge constant $\left(\mathrm{s} \mathrm{m}^{-1}\right)^{\dagger}$ & - & - & 0.26 & 0.26 & 0.39 & 0.31 \\
& - & - & 0.17 & 0.17 & 0.20 & 0.18
\end{tabular}

- Difference between two samples, one at the beginning and the other at the end of the period. No melting occurred.

\# Totalizer reading not corrected for evaporation.

\#.* Totalizer reading not corrected for evaporation.
Assumed 1 for snow sampling (above), and for snow pillow (below).

+ Assumed 1 for snow sampling (above), and for snow pillow (below).
+ Computed from catch efficiency $=1 /\left(1+G^{*} U\right)$, where $U$ is the wind speed in $\mathrm{m} \mathrm{s}^{-1}$ and $G$ the gauge constant in $\mathrm{s} \mathrm{m}^{-1}$. Average wind speed was $4.2 \mathrm{~m} \mathrm{~s}^{-1}$. 


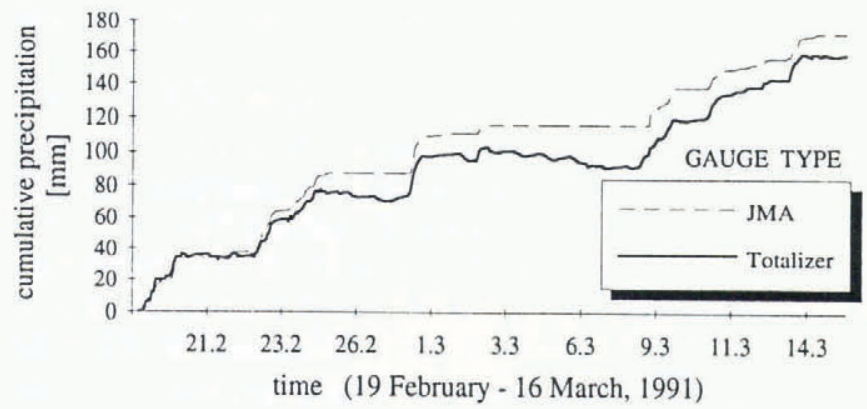

Fig. 2. Accumulated precipitation for the Joetsu test site, 1991, as measured with the newly developed totalizer and the Japan Meteorological Agency (JMA) standard gauge.

With these measurements, we aimed to achieve two objectives :

To assess the instrument's ability to measure collected precipitation when mixed with antifreeze solution; and

to discover operational correction procedures for our instrument that are accurate and readily applicable.

\section{Results and discussion}

The first year's trial showed that the antifreeze solution and pressure-sensor system worked satisfactorily to melt snow and to detect the amount of water thus accumulated. All the gauges compared performed similarly during the seven-day period when two major snowfall events occurred (Table 1; Fig. 2). Low catch efficiency, $50-60 \%$ (Table 1), was probably due to the strong wind, which over this period averaged $4.2 \mathrm{~m} \mathrm{~s}^{-1}$.

The 1991 winter data also suggest that there were some apparent malfunctions in the newly developed instrument (Fig. 2). One is a systematic decline in the amount of water collected in dry periods. This was primarily due to the fact that the oil used (DOA oil, density $0.93 \mathrm{~g} \mathrm{~cm}^{-3}$ ) did not sufficiently prevent evaporation of ethanol and water. In a laboratory experiment a water - antifreeze solution was covered by $3.5 \mathrm{~mm}$ DOA oil. After one month all ethanol had evaporated. Superimposed on evaporation was insufficient temperature compensation for the quartz-crystal pressure sensor.

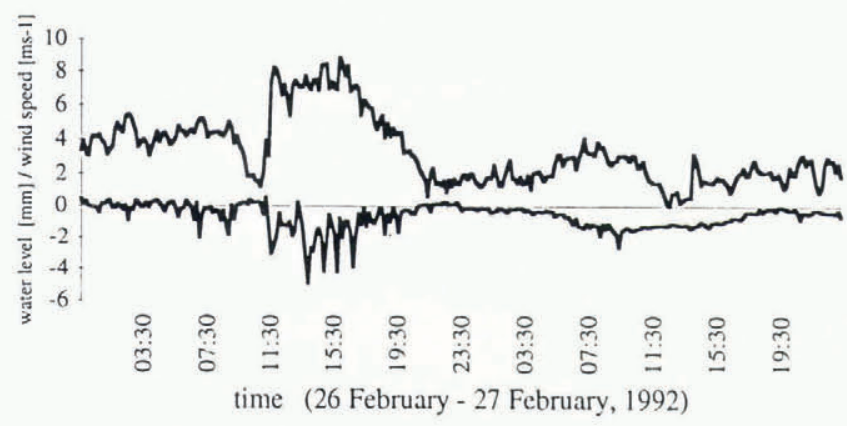

Fig. 3. Effect of wind on the pressure measurement displayed as water level ( $\mathrm{mm}$ ). Strong wind causes depression in the gauge. The effect of the building in which the reference atmospheric pressure was measured is superimposed.
Rapid fluctuations in the sensor output also appeared from time to time (Fig. 2), owing to the effects of strong wind (Fig. 3).

Having replaced the evaporation retardant with engine oil (brand Pan-S, $10 \mathrm{~W}-30$, density $0.88 \mathrm{~g} \mathrm{~cm}^{-3}$ ) and improved the temperature correction, we confirmed that the instrument performed satisfactorily over more than a month in the 1992 winter (Fig. 4). Accumulated precipitation measured by our instrument and the JMA standard were identical for most of the time, indicating that the instrument was comparable to the standard gauge with regard to both catch and detection capabilities.

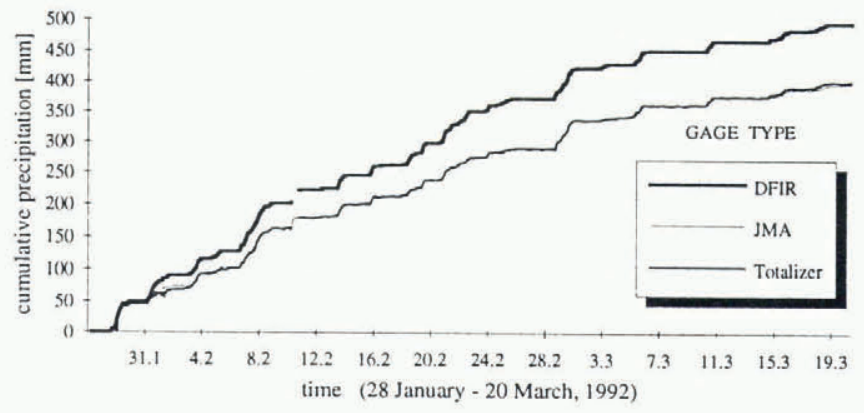

Fig. 4. Accumulated precipitation for the Joetsu test site, 1992, as measured with three gauges.

As noted above, the sensor output fluctuated in response to wind. Statistical analysis on the relation between the pressure and wind speed (Fig. 5) showed that the standard deviation of the water-level change $(\sigma$, calculated from 20 samples collected within $10 \mathrm{~min}$, in $\mathrm{mm})$ increases quadratically with wind speed $\left(U \mathrm{~m} \mathrm{~s}^{-1}\right)$ :

$$
\sigma=0.011 U^{2} \text {. }
$$

This result implies that the instrument provides a measure of wind speed that is used to correct for wind-caused undermeasurement.

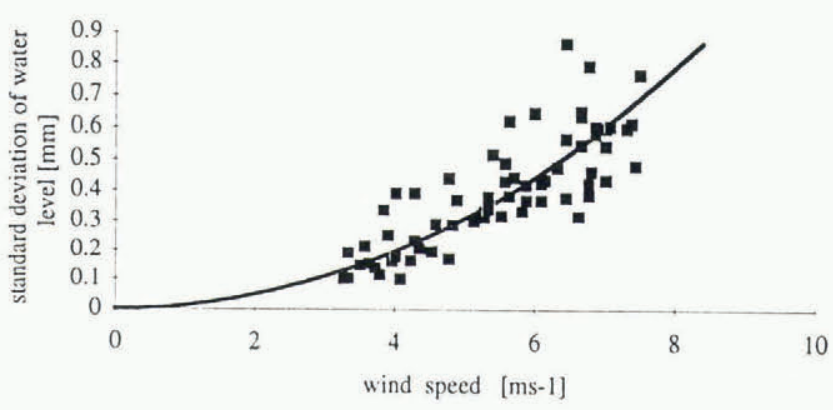

Fig. 5. The standard deviation of water-level fluctuation calculated from 20 measurements over 10 min as a function of wind speed.

\section{CONCLUSIONS}

Field-testing over two winters demonstrated that the newly developed totalizer performed satisfactorily. Both response to the onset of a precipitation event and accuracy of measurement were comparable to the JMA 
standard gauge. Furthermore, it was capable of detecting wind speed simultaneously. This feature is particularly noteworthy since it provides the possibility that the totalizer can operate as a "self-correcting" precipitation gauge. Wind is a major source of error in precipitation gauge measurements (Goodison and others, 1981). Thus we can assume that catch efficiency is a function of wind speed $U\left(\mathrm{~m} \mathrm{~s}^{-1}\right)$ (e.g. Dahlström, 1986).

$$
C E=f(G, U)
$$

where $C E$ is catch efficiency and $G$ is the "gauge constant" that is dependent on both gauge configuration and precipitation form. Since the totalizer we have developed is able to detect wind speed $(U)$ as well, $C E$ could be computed continously if the value of $G$ is specified. This, in turn, enables the instrument to provide corrected precipitation for catch deficiency automatically.

\section{REFERENCES}

Dahlström, B. 1986. The improvement of point precipitation data on an operational basis - a modular concept. Zürcher Geogr. Schr. 23, 125-129.

Foehner, O.H. 1978. Developing techniques for measur- ing precipitation. Proc. West. Snow Conf., 46th Annual Meeting, 26-32.

Goodison, B.E., H. L. Ferguson and G. A. McKay. 1981. Measurement and data analysis. In Gray, D. M. and D. H. Male, eds. Handbook of snow; principles, processes, management and use. Toronto, Pergamon Press, 191-274. Huovila, S., E. Elomaa, K. Leminen, B. Tammelin and A. Tuominen. 1988. Comparison of snow gauges used in Nordic countries - contribution of Finland to WMO Solid Precipitation Measurement Intercomparison. Part I. System description. Helsinki, Finnish Meteorological Institute. (Meteorological Publication 9.)

Larson, L.W. 1986. Experience, investigations and recommendations concerning wind induced precipitation measurements errors. Zürcher Geogr. Schr. 23, 4956.

Sevruk, B. 1986. Correction of precipitation measurements (summary report). Zürcher Geogr. Schr. 23, 13-23.

WMO. 1985. International Organizing Committee for WMO Solid Precipitation Measurement Intercomparison. Final report of first session. Geneva, World Meteorological Organization.

The accuracy of references in the text and in this list is the responsibility of the authors, to whom queries should be addressed. 